\title{
Environmental Factors Affecting the Survival of Juveniles and Recent Returns of Chum Salmon in the Okhotsk Coast of Hokkaido
}

\author{
Yasuyuki Miyakoshi, Hayato Saneyoshi, and Yousuke Koshino \\ Salmon and Freshwater Fisheries Research Institute, Hokkaido Research Organization, 3-373 Kitakashiwagi, \\ Eniwa, Hokkaido 061-1433, Japan
}

Keywords: chum salmon, Hokkaido, Okhotsk Sea, warm current

The Okhotsk coast of Hokkaido is the principal area of chum salmon, Oncorhynchus keta, production in Japan. In recent years, returns of chum salmon to the Okhotsk coast have been reaching historic highs, although decreases of chum salmon on the other coasts of Hokkaido have been remarkable since 2008 (Miyakoshi et al. 2013). The early marine phase is considered the critical period for the survival of chum salmon, that determines the subsequent number of fish returned. One of the likely causes for the regional difference in return rates is the recent changes in the coastal environment around the time that juvenile salmon migrate into the area (Nagata et al. 2016a). The recent high abundance of chum salmon in the Okhotsk coast should be due to the favorable ocean conditions and successful enhancement program. However, the returns of chum salmon to the Okhotsk coast of Hokkaido have decreased since 2014; with extreme low returns of the 2010, 2012, and 2013 brood year classes were observed.

In the coastal waters of Abashiri on the eastern Okhotsk coast of Hokkaido (Fig. 1), we have conducted a field survey since 2002 to monitor seawater temperature, salinity, zooplankton abundance, and density of juvenile chum salmon from late April to early July (Nagata et al. 2007). The coastal environmental conditions in the Okhotsk coast are affected by the warm oceanic current called the "Soya Warm Current", which is defined by high salinity (> 33.6psu) (Asami et al. 2007). In this study, we examined the effects of such environmental factors on the survival of chum salmon on the eastern Okhotsk coast of Hokkaido.

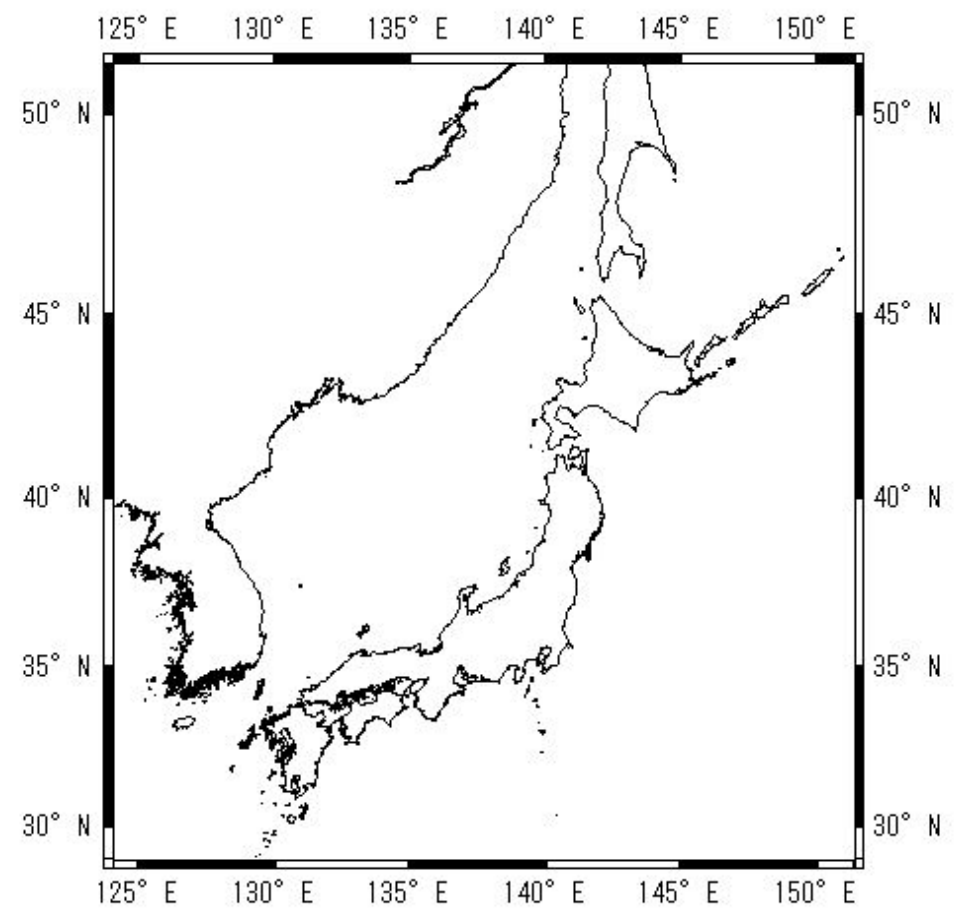

Fig. 1. Study area for environmental factors and returns of chum salmon in eastern Hokkaido.

When the effects of the environmental factors were examined, a significant relationship was observed between seawater temperature in May and number of chum salmon returned $\left(R^{2}=0.422, p<0.05\right)$, but there were no significant relationships for seawater temperature in June, or zooplankton abundance. Also, numbers of juvenile chum salmon captured in the coastal area by trawl survey and numbers of returns of the brood year were weakly 
correlated $\left(R^{2}=0.420, p<0.05\right)$. This may indicate sea water temperature just after ocean entry may be an important factor affecting the survival of juvenile chum salmon. Zooplankton biomass in this region may be abundant enough for juvenile chum salmon even in the years of low abundance; as a result, yearly fluctuation of zooplankton biomass did not have a significant effect on the numbers of returning chum salmon in this region.

When the Soya Warm Current was weak $(2011,2014)$, the returns of chum salmon of the brood year classes tended to be low, although its effects were not significant. The flow of the Soya Warm Current is weak in winter and expands in spring and early summer. The expansion of the Soya Warm Current affected the seawater temperature, salinity, and abundance and composition of zooplankton in the coastal area where juvenile chum salmon distribute (Asami et al. 2007). These former studies indicated that the seawater temperature affects the return rates of chum salmon in this region (Miyakoshi et al. 2007; Nagata et al. 2016b). The timing of the expansion of the Soya Warm Current may relate to the distribution, the timing of offshore migration of juvenile chum salmon, and the subsequent survivals in the Okhotsk coast of Hokkaido.

\section{REFERENCES}

Asami, H., H. Shimada, M. Sawada, H. Sato, Y. Miyakoshi, D. Ando, M. Fujiwara, and M. Nagata. 2007. Influence of physical parameters on zooplankton variability during early ocean life of juvenile chum salmon in the coastal waters of eastern Hokkaido, Okhotsk Sea. N. Pac. Anadr. Fish Comm. Bull. 4: 211-221.

Miyakoshi, Y., M. Nagata, and S. Saitoh. 2007. Sea surface temperature measured by satellite remote sensing and its effect on the return rate of chum salmon in the eastern region along the Okhotsk Sea. Scientific Reports of the Hokkaido Fish Hatchery 61: 1-10 (in Japanese with English abstract).

Miyakoshi, Y., Nagata, M., Kitada, S., and Kaeriyama, M. 2013. Historical and current hatchery programs and management of chum salmon in Hokkaido, northern Japan. Rev. Fish. Sci. 21: 469-479.

Nagata, M., Y. Miyakoshi, D. Ando, M. Fujiwara, M. Sawada, H. Shimada, and H. Asami. 2007. Influence of coastal seawater temperature on the distribution and growth of juvenile chum salmon, with recommendations for altered release strategies. N. Pac. Anadr. Fish Comm. Bull. 4: 223-235. (Available at http://www.npafc.org)

Nagata, M., Y. Miyakoshi, M. Fujiwara, K. Kasugai, D. Ando, M. Torao, H. Saneyoshi, and J.R. Irvine. 2016a. Adapting Hokkaido hatchery strategies to regional ocean conditions can improve chum salmon survival and reduce variability. NPAFC Bull. 6: 73-85. (Available at http://www.npafc.org)

Nagata, M., D. Ando, M. Fujiwara, and Y. Miyakoshi. 2016b. Effects of release timing on the recovery of late-run chum salmon in the Okhotsk Sea coast of Hokkaido, Japan. NPAFC Bull. 6: 87-95. (Available at http://www.npafc.org) 